\title{
Sistema radicular de cultivares de feijão em resposta à calagem
}

\author{
Laerte Marques da Silva ${ }^{(1)}$, Leandro Borges Lemos $^{(1)}$, Carlos Alexandre Costa Crusciol(1) ${ }^{(1)}$ José Carlos Feltran ${ }^{(1)}$ \\ (1)Universidade Estadual Paulista, Fac. de Ciências Agronômicas, Dep. de Produção Vegetal, Caixa Postal 237, CEP 18603-970 Botucatu, SP. \\ E-mail: laertemarques@fca.unesp.br, leandrobl@fca.unesp.br, feltranjc@fca.unesp.br, crusciol@fca.unesp.br
}

\begin{abstract}
Resumo - O crescimento radicular apresenta variabilidade genética, e é afetado pelo Al tóxico e baixos teores de $\mathrm{Ca}$ e $\mathrm{Mg}$ do solo, que podem comprometer o seu desenvolvimento. O objetivo deste trabalho foi avaliar o sistema radicular de cultivares de feijão em resposta à calagem. $O$ experimento foi realizado em vasos de $13 \mathrm{dm}^{3}$ de solo, em casa de vegetação, até 43 dias após a emergência das plantas. O delineamento experimental utilizado foi o inteiramente casualizado, em arranjo fatorial $4 \times 4$, composto por quatro doses de calcário $(0,1,59,3,18 \mathrm{e}$ 4,48 $\mathrm{t} \mathrm{ha}^{-1}$ ) e quatro cultivares de feijão (Campeão 1, Carioca, FT-Bonito e Pérola), com quatro repetições. O sistema radicular da cultivar Pérola foi mais tolerante à baixa saturação por bases do que o das demais cultivares. O máximo crescimento radicular das cultivares Campeão 1, Carioca e Pérola ocorreu em saturação por bases ao redor de $43 \%$. Em condições de elevada acidez, o diâmetro radicular das cultivares é reduzido e há um incremento em comprimento. A calagem promove aumento do sistema radicular e da parte aérea das cultivares.

Termos para indexação: Phaseolus vulgaris, alumínio, solo ácido, toxidez, sistema radicular.
\end{abstract}

\section{Root system of common bean cultivars as response of liming}

\begin{abstract}
Root growth is genetically controlled and the variability among cultivars and soil factors, such as $\mathrm{Al}$ toxicity and low $\mathrm{Ca}$ and $\mathrm{Mg}$ contents, can damage it. The objective of this study was to evaluate root growth and shoot growth of bean cultivars in response to liming. The experiment was carried out in pots with $13 \mathrm{dm}^{3}$ of soil, in greenhouse until 43 days after the emergence of the plants. The experimental design was a completely randomized block, in a factorial scheme $4 \times 4$, with four doses of line $\left(0,1.59,3.18\right.$ and $\left.4.48 \mathrm{t} \mathrm{ha}^{-1}\right)$, four bean cultivars (Campeão 1, Carioca, FT-Bonito and Pérola), and four replications. Pérola cultivar presents a root system more tolerant to low base saturation in comparison to the others. The maximum root growth occurred in base saturation values around 43\% for Campeão 1, Carioca and Pérola cultivars. Under high acidity conditions, bean cultivars reduce root diameter and increase root length. Liming improves the root system growth and the aerial parts growth of the cultivars.
\end{abstract}

Index terms : Phaseolus vulgaris, aluminium, acid soil, toxicity, root system.

\section{Introdução}

Inforzato \& Miyasaka (1963) verificaram, sob condições tropicais, que o sistema radicular do feijoeiro comum (Phaseolus vulgaris L.) é superficial, e que na floração mais de $83 \%$ da biomassa radicular concentrase na camada de $0-20 \mathrm{~cm}$ do solo. Lynch \& Beem (1993) constataram variabilidade genotípica entre cultivares de feijão em relação ao número de raízes basais, à massa de matéria seca e ao comprimento radicular. Wutke et al. (2003) verificaram diferenças significativas entre as cultivares de feijão Carioca e IAC Carioca Pyatã quanto à quantidade de raízes e à profundidade efetiva do sistema radicular, na safra da seca, sem irrigação e após o cultivo de feijão-de-porco, em plantio direto. Embora o sistema radicular esteja sob controle genético, o seu crescimento é influenciado por fatores químicos, físicos e biológicos do solo (Taylor \& Arkin, 1981), além da temperatura, estresse hídrico e de práticas culturais, como a aplicação de calcário e fertilizantes (Rosolem, 1996; Fageria \& Stone, 1999).

$\mathrm{Na}$ maioria dos solos brasileiros, o teor de Al é elevado, o que limita o desenvolvimento do sistema radicular e, conseqüentemente, reduz a absorção, transporte e utilização dos nutrientes, diminuindo a produtividade das culturas (Silva et al., 1984).

Fageria \& Stone (1999) relataram que, culturas como arroz, amendoim, batata, caupi, mandioca, milheto e guandu são relativamente tolerantes à acidez do solo, enquanto o feijoeiro, a soja, o sorgo e o trigo são suscetíveis. Segundo Thung \& Oliveira (1998), na cultura do feijão, o conceito de utilização de plantas mais toleran- 
tes à toxicidade de $\mathrm{Al}$ não está bem caracterizado, já que, mesmo nas cultivares Carioca e Rio Tibagi, classificadas como tolerantes, embora a maioria dos resultados não revelem diferenças no crescimento, elas apenas apresentaram maior produtividade de grãos que as demais cultivares.

Sousa Júnior et al. (1998), em solução nutritiva, constataram que as cultivares de feijão Milionário e Mulatinho, na presença de $\mathrm{Al}$ e doses de $\mathrm{Ca}$ e de $\mathrm{Mg}$, aumentaram a produção de matéria seca do sistema radicular com o aumento dos teores de cálcio.

Apesar de os sintomas de toxicidade de Al se manifestarem primeiramente no sistema radicular, a determinação somente da massa de matéria seca da raiz não é suficiente para avaliar o efeito danoso desse elemento, sendo necessário quantificar também o comprimento e a produtividade de massa de matéria seca das raízes grossas e finas (Silva et al., 1984).

Segundo Ritchey et al. (1982), o Ca é essencial ao crescimento do sistema radicular. Conforme Rosolem (1996), a calagem na cultura do feijão promove modificações no sistema radicular, além de fornecer $\mathrm{Ca}$ e $\mathrm{Mg}$, e aumenta o $\mathrm{pH}$, que por sua vez, aumenta a disponibilidade de nutrientes. Esse mesmo autor destaca que é importante que o cultivo do feijoeiro seja feito em solos com pH em água na faixa de 6,0 a 6,5. Segundo o mesmo autor, nessa faixa de $\mathrm{pH}$, a fixação simbiótica do $\mathrm{N}_{2}$ é mais eficiente e a fitotoxicidade do $\mathrm{Al}$ e $\mathrm{Mn}$ é nula, o que permite maior desenvolvimento do sistema radicular, tornando a planta mais apta para produzir em condições de défict hídrico. Fageria \& Stone (1999) constataram que o sistema radicular do feijoeiro aumentou até $\mathrm{pH}$ de 5,9 , por causa do efeito da calagem e da aplicação de $P$ que proporcionaram maior absorção de nutrientes e água do solo.

O objetivo deste trabalho foi avaliar o sistema radicular de cultivares de feijão em resposta à calagem.

\section{Material e Métodos}

O experimento foi realizado em casa de vegetação, no Departamento de Produção Vegetal, da Faculdade de Ciências Agronômicas/Unesp, Campus de Botucatu, SP (2251' S, 48²6' W; $740 \mathrm{~m}$ de altitude). O delineamento experimental utilizado foi inteiramente casualizado, com quatro repetições, em arranjo fatorial $4 \times 4$, constituído por quatro cultivares de feijão do grupo comercial carioca (Campeão 1, Carioca, FT-Bonito e Pérola) e quatro doses de calcário $(0,1,59,3,18$ e $4,48 \mathrm{t} \mathrm{ha}^{-1}$ ), com quatro repetições. As doses de calcário foram aplicadas com a finalidade de elevar a saturação por bases (V\%) para 3\%, 18\%, 33\% e 45\%, respectivamente.

O solo utilizado foi proveniente da camada arável (0-20 cm) de um Latossolo Vermelho distrófico (Embrapa, 1999), com 680, 150 e $170 \mathrm{~g} \mathrm{~kg}^{-1}$ de areia, silte e argila, respectivamente, cujas características químicas, determinadas conforme Raij et al. (2001), são apresentadas na Tabela 1.

A terra foi peneirada em malha de $4 \mathrm{~mm}$, secada ao ar e colocada em sacos de plástico com volume de $13 \mathrm{dm}^{3}$. A calagem constou da mistura de calcário dolomítico $(\mathrm{PRNT}=91 \%)$ com solo. A seguir, aplicaram-se $100 \mathrm{mg} \mathrm{dm}^{-3}$ de $\mathrm{P}, 100 \mathrm{mg} \mathrm{dm}^{-3} \mathrm{de} \mathrm{K}$, nas formas de fosfato monoamônico e cloreto de potássio, respectivamente. As doses de calcário e dos fertilizantes foram misturadas à terra dos sacos de plástico e transferidas para os vasos. A seguir, adicionou-se água em cada vaso, equivalente a $80 \%$ da água disponível total (ADT). O período de incubação foi de 30 dias, após o qual foi coletada uma amostra composta do solo de cada tratamento para análise química (Raij et al., 2001), cujos resultados são apresentados na Tabela 1.

Por ocasião da semeadura, aplicaram-se $3 \mathrm{mg} \mathrm{dm}^{-3}$ de $\mathrm{Zn}$ (sulfato de zinco) e $50 \mathrm{mg} \mathrm{dm}^{-3}$ de $\mathrm{N}$ (uréia).

Tabela 1. Atributos químicos do solo, antes e após 30 dias da calagem.

\begin{tabular}{lccccc}
\hline Atributo & Antes & \multicolumn{4}{c}{ Calcário $\left(\mathrm{t} \mathrm{ha}^{-1}\right)$} \\
\cline { 3 - 6 } & da calagem & 0 & 1,59 & 3,18 & 4,48 \\
\hline $\mathrm{MO}\left(\mathrm{g} \mathrm{kg}^{-1}\right)$ & 22 & $-^{(1)}$ & - & - & - \\
$\mathrm{pH}\left(\mathrm{CaCl}_{2}\right)$ & 4,0 & 4,0 & 4,3 & 4,9 & 5,1 \\
$\mathrm{P}_{\text {resina }}\left(\mathrm{g} \mathrm{dm}^{-3}\right)$ & 2 & 114 & 108 & 108 & 109 \\
$\mathrm{~K}\left(\mathrm{mmol}_{\mathrm{c}} \mathrm{dm}^{-3}\right)$ & 0,5 & 3,6 & 3,4 & 3,1 & 3,5 \\
$\mathrm{Ca}\left(\mathrm{mmol}_{\mathrm{c}} \mathrm{dm}^{-3}\right)$ & 2,0 & 5 & 12 & 21 & 25 \\
$\mathrm{Mg}\left(\mathrm{mmol}_{\mathrm{c}} \mathrm{dm}^{-3}\right)$ & 0,2 & 0,8 & 3,2 & 6,6 & 8,0 \\
$\mathrm{H}+\mathrm{Al}\left(\mathrm{mmol}_{\mathrm{c}} \mathrm{dm}^{-3}\right)$ & 97 & 87 & 68 & 53 & 45 \\
$\mathrm{SB}\left(\mathrm{mmol}_{\mathrm{c}} \mathrm{dm}^{-3}\right)$ & 2,7 & 9 & 18 & 31 & 36 \\
$\mathrm{CTC}\left(\mathrm{mmol}_{\mathrm{c}} \mathrm{dm}^{-3}\right)$ & 99,7 & 96 & 86 & 84 & 81 \\
$\mathrm{~V}(\%)$ & 3 & 10 & 21 & 36 & 44 \\
$\mathrm{Al}\left(\mathrm{mmol}_{\mathrm{c}} \mathrm{dm}^{-3}\right)$ & 29 & 24 & 18 & 13 & 11 \\
$\mathrm{~m}(\%)$ & 30 & 25 & 20 & 15 & 13 \\
$\mathrm{Cu}\left(\mathrm{mg} \mathrm{dm}^{-3}\right)$ & 0,5 & 2,7 & 1,9 & 2,3 & 2,3 \\
$\mathrm{Zn}\left(\mathrm{mg} \mathrm{dm}^{-3}\right)$ & 0,6 & 1,4 & 1,2 & 1,1 & 1,1 \\
$\mathrm{Fe}\left(\mathrm{mg} \mathrm{dm}^{-3}\right)$ & 22 & 43 & 39 & 36 & 32 \\
$\mathrm{Mn}\left(\mathrm{mg} \mathrm{dm}^{-3}\right)$ & 0,4 & 0,7 & 0,7 & 0,5 & 0,5 \\
\hline
\end{tabular}

${ }^{(1)}$ Não determinado. 
A semeadura foi realizada em 24/4/2001, utilizando seis sementes por vaso. Com as sementes, aplicou-se fungicida thiram (150 mL $100 \mathrm{~kg}^{-1}$ sementes), para o controle preventivo da antracnose (Colletotrichum lindemuthianum) e podridão-radicular (Rhizoctonia solani). Uma semana após a emergência, foi realizado desbaste, restando três plantas por vaso. Aos 25 dias após a emergência (DAE), aplicaram-se em cobertura $100 \mathrm{mg} \mathrm{dm}^{-3}$ de $\mathrm{N}$ (uréia) em cada vaso.

O controle fitossanitário foi realizado mediante duas pulverizações, aos 27 DAE com inseticida triazophós (0,9 $\left.\mathrm{L} \mathrm{ha}^{-1}\right)$ para controle da mosca-minadora (Liriomyza sp.) e do ácaro-branco (Polyphagotarsonemus latus), e aos 33 DAE com fungicida óxido cuproso (1.100 $\mathrm{g} \mathrm{ha}^{-1}$ ) para o controle do oídio (Erysiphe polygoni).

As temperaturas de $22^{\circ} \mathrm{Ce} 29^{\circ} \mathrm{C}$ foram fixadas como mínima e máxima, respectivamente. A necessidade de irrigação foi detectada mediante pesagem diária de quatro vasos para cada dose de calcário, colocando-se água em quantidade suficiente para elevar a umidade a $100 \%$ da ADT sempre que o nível atingia $80 \%$ da ADT. $O$ rodízio dos vasos foi realizado semanalmente.

Aos 43 DAE, quando a maioria das plantas encontrava-se no estádio fenológico de floração $\left(\mathrm{R}_{6}\right)$, as plantas foram seccionadas na altura do colo, e a parte aérea lavada e secada em estufa com circulação forçada de ar a $70^{\circ} \mathrm{C}$, até massa constante, visando obter a massa de matéria seca da parte aérea. Após, foi retirado o solo de cada vaso e as raízes separadas por lavagem em água corrente sobre peneira de $0,5 \mathrm{~mm}$ de malha. Foi tomada, no sentido longitudinal, uma subamostra das raízes (aproximadamente 1/8 do total), colocada em frasco com álcool $50 \%$ e armazenada sob refrigeração. O restante das raízes foi secado em estufa com ventilação forçada a $70^{\circ} \mathrm{C}$ até massa constante, de forma a se definir a massa de matéria seca.

As amostras acondicionadas em álcool foram utilizadas na determinação do comprimento total, área superficial, volume total e diâmetro médio por meio da digitalização de imagem, utilizando scanner HP Scanjet 4c/T e o software WinRHIZO Reg. 3.8b (Regent Instruments Inc.). Após essas determinações as amostras foram secadas em estufa até massa constante e pesadas, sendo obtida a massa de matéria seca das raízes.

Os resultados foram submetidos à análise de variância e as médias comparadas pelo teste de Tukey a $5 \%$ de probabilidade. Quanto às doses de calcário e ao desdo- bramento da interação das doses de calcário dentro de cultivares, adotou-se análise de regressão, e a equação mais adequada foi definida primeiramente pelo efeito significativo e posteriormente pelo maior valor do coeficiente de determinação $\left(\mathrm{R}^{2}\right)$.

\section{Resultados e Discussão}

O aumento das doses de calcário proporcionou elevação do $\mathrm{pH}, \mathrm{Ca}$ e $\mathrm{Mg}$ trocáveis e redução nos teores de $\mathrm{Al}$ trocável e $\mathrm{H}+\mathrm{Al}$, evidenciando o efeito positivo dessa prática (Tabela 1). Resultados semelhantes foram observados por Adams \& Moore (1983), Rosolem, (1996), Rosolem et al. (1998, 2000).

Houve efeito significativo das cultivares em relação à superfície e ao volume do sistema radicular; da calagem em todas as variáveis estudadas; e da interação entre o comprimento e volume radicular (Tabela 2). A cultivar FT-Bonito apresentou maior superfície radicular do que a cultivar Pérola. Também a cultivar FT-Bonito alcançou maior volume radicular, diferindo das demais cultivares.

Quanto ao comprimento radicular, as cultivares apresentaram resposta positiva e quadrática aos níveis de calcário, exceto a cultivar FT-Bonito que respondeu linearmente (Figura 1). Na ausência da calagem, os maiores valores de comprimento radicular foram alcançados pelas cultivares Pérola $(2.266 \mathrm{~cm})$ e Carioca $(955 \mathrm{~cm})$.

A resposta positiva do crescimento radicular ao aumento dos teores de $\mathrm{Ca}$ e $\mathrm{Mg}$ está relacionada à síntese da parede celular, uma vez que estes nutrientes participam da formação dos compostos de pectatos de $\mathrm{Ca}$ e Mg (Malavolta, 1980), além da redução no teor de alu-

Tabela 2. Comprimento, superfície, volume e diâmetro do sistema radicular, no período de florescimento $\left(\mathrm{R}_{6}\right)$ de cultivares (C) de feijão, em razão das doses de calcário (DC) ${ }^{(1)}$.

\begin{tabular}{|c|c|c|c|c|}
\hline Cultivar & $\begin{array}{l}\text { Comprimento } \\
\left.(\mathrm{cm} \mathrm{planta})^{-1}\right)\end{array}$ & $\begin{array}{c}\text { Superfície } \\
\left(\mathrm{cm}^{2} \text { planta }^{-1}\right)\end{array}$ & $\begin{array}{c}\text { Volume } \\
\left(\mathrm{cm}^{3} \text { planta }^{-1}\right)\end{array}$ & $\begin{array}{c}\text { Diâmetro } \\
(\mathrm{mm})\end{array}$ \\
\hline Campeão 1 & $12.714 \mathrm{a}$ & $3.595 \mathrm{ab}$ & $50,48 b$ & $0,09 a$ \\
\hline Carioca & $10.997 \mathrm{a}$ & $3.399 \mathrm{ab}$ & $47,49 b$ & $0,09 \mathrm{a}$ \\
\hline FT-Bonito & $12.782 \mathrm{a}$ & $4.185 \mathrm{a}$ & $99,44 a$ & $0,09 \mathrm{a}$ \\
\hline Pérola & $10.943 \mathrm{a}$ & $3.025 b$ & $68,85 b$ & $0,08 \mathrm{a}$ \\
\hline $\mathrm{C}$ & $2,12^{\mathrm{ns}}$ & $3,61 *$ & $14,71 * *$ & $1,61^{\mathrm{ns}}$ \\
\hline DC & $114,6 * *$ & $78,04 * *$ & $51,57 * *$ & $15,78 * *$ \\
\hline $\mathrm{C} \times \mathrm{DC}$ & $4,43 * *$ & $1,85^{\mathrm{ns}}$ & $2,93 * *$ & $1,14^{\mathrm{ns}}$ \\
\hline CV (\%) & 23,77 & 28,71 & 37,39 & 12,34 \\
\hline
\end{tabular}

${ }^{(1)}$ Médias seguidas da mesma letra, na coluna, não diferem entre si pelo

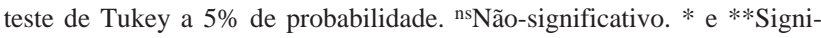
ficativo a $5 \%$ e a $1 \%$ de probabilidade, respectivamente, pelo teste F. 

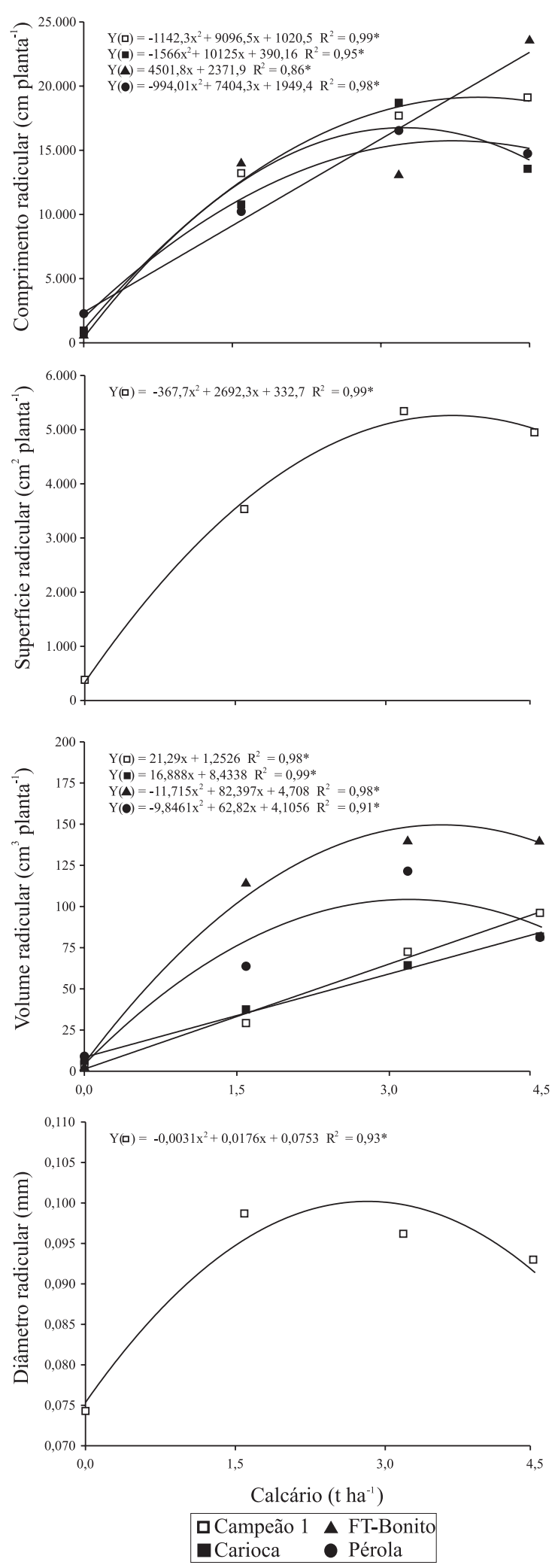

Figura 1. Comprimento, superfície, volume e diâmetro radicular de cultivares de feijão, em razão das doses de calcário. mínio. Esses resultados corroboram os de Rosolem (1989), que determinou como nível crítico de Ca para o crescimento radicular do milho o teor de $5 \mathrm{mmol}_{\mathrm{c}} \mathrm{dm}^{-3}$. Apesar de não terem sido encontrados trabalhos que correlacionassem o crescimento das raízes do feijoeiro com o teor de $\mathrm{Ca}$ do solo, vários autores verificaram o efeito benéfico da calagem no crescimento radicular do feijoeiro (Fageria et al., 1989; Fageria \& Stone, 1999), da soja (Rosolem \& Marcello, 1998), do milho (Rosolem et al., 1994) e do algodão (Rosolem et al., 2000).

A superfície radicular aumentou com o incremento das doses de calcário até 3,7 t ha ${ }^{-1}$ (Figura 1). A resposta no aumento da superfície radicular ocorre em virtude do maior comprimento radicular causado pelo incremento das doses de calcário. Assim, o aumento do comprimento das raízes decorrente da calagem e, conseqüentemente, da superfície radicular do feijoeiro torna-se um fator benéfico, uma vez que, com maior superfície de contato, as raízes têm melhores condições de absorção de nutrientes e água da solução do solo, o que pode resultar em estabilidade de produtividade.

Quanto ao volume radicular, verificou-se nas cultivares FT-Bonito e Pérola resposta positiva e quadrática aos níveis de calcário, enquanto na Campeão 1 e na Carioca a resposta foi positiva e linear (Figura 1). $\mathrm{Na}$ ausência da calagem, as cultivares Pérola e FT-Bonito apresentaram os maiores e menores valores de volume radicular, respectivamente. No entanto, as cultivares FT-Bonito e Pérola apresentaram maiores valores de volume radicular com o aumento das doses de calcário até aproximadamente $3,3 \mathrm{tha}^{-1}$. Este aumento de volume radicular está relacionado ao incremento do comprimento e superfície radicular.

O diâmetro radicular do feijoeiro não foi afetado pela interação entre cultivares e doses de calcário e sim pelas doses de calcário (Tabela 2), com reposta positiva e quadrática (Figura 1). Na ausência de calagem, o diâmetro radicular apresentou os menores valores, o que pode ser atribuído à habilidade adquirida à custa do crescimento em extensão do sistema radicular (Tiffney \& Niklas, 1985), possibilitando exploração de maior volume de solo pelas raízes e, consecutivamente, aumento da superfície específica, com melhoria na absorção dos nutrientes.

Nas cultivares de feijão, foram observadas diferenças significativas em relação à massa de matéria seca do sistema radicular e massa de matéria seca total. 
Apesar de as doses de calcário afetarem todas as variáveis, somente a massa de matéria seca do sistema radicular foi influenciada pela interação entre cultivares e doses de calcário (Tabela 3 e Figura 2).

A cultivar FT-Bonito produziu maior quantidade de massa de matéria seca radicular e de massa de matéria seca total. Esse resultado pode ser decorrente dos maiores valores da superfície e volume radicular, culminando na diferença em relação à variável massa de matéria seca radicular e massa de matéria seca total.

A calagem proporcionou aumentos significativos de forma quadrática em relação à massa de matéria seca do sistema radicular, massa de matéria seca da parte aérea e massa de matéria seca total (Figura 2), atingindo valores máximos nas doses de 3,0 a 4,4 t ha-1. Os resultados da massa de matéria seca da parte aérea corroboram os de Fageria et al. (1989).

$\mathrm{Na}$ ausência de calagem, a cultivar Pérola apresentou maior produção de massa de matéria seca radicular, e os menores valores registrados foram na Carioca, com 0,25 e $0,09 \mathrm{~g}$, respectivamente (Figura 2). No entanto, com o aumento das doses de calcário, a maior produtividade de massa de matéria seca radicular foi alcançada pela cultivar FT-Bonito. A produção de massa de matéria seca radicular aumentou em todas as cultivares e o máximo valor foi alcançado quando a saturação por bases era de 43\%. Vale (1994) também constatou que a estabilidade no crescimento do sistema radicular do feijoeiro foi alcançada quando a saturação por bases foi elevada de $40 \%$ para $46 \%$. Em cultivo de feijão irriga-

Tabela 3. Matéria seca da raiz, da parte aérea e matéria seca total, no período de florescimento $\left(\mathrm{R}_{6}\right)$ de cultivares de feijão, em razão das doses de calcário ${ }^{(1)}$.

\begin{tabular}{|c|c|c|c|}
\hline Variável & Raiz & Parte aérea & Total \\
\hline & \multicolumn{3}{|c|}{------------- $\left(\right.$ g planta $\left.^{-1}\right)$---------' } \\
\hline Campeão 1 & $1,23 b$ & $3,19 \mathrm{a}$ & $4,43 \mathrm{ab}$ \\
\hline Carioca & $1,15 b$ & $3,43 a$ & $4,59 \mathrm{ab}$ \\
\hline FT-Bonito & $1,60 \mathrm{a}$ & $3,35 \mathrm{a}$ & $5,06 \mathrm{a}$ \\
\hline Pérola & $1,09 \mathrm{~b}$ & $3,06 \mathrm{a}$ & $4,26 \mathrm{~b}$ \\
\hline$\overline{\text { Cultivar (C) }}$ & $6,05 * *$ & $1,19^{\text {ns }}$ & $4,05^{*}$ \\
\hline Dose de calcário (DC) & $72,02 * *$ & $299,12 * *$ & $276,51^{* *}$ \\
\hline $\mathrm{C} \times \mathrm{DC}$ & $2,31 *$ & $1,91^{\mathrm{ns}}$ & $1,07^{\mathrm{ns}}$ \\
\hline $\mathrm{CV}(\%)$ & 29,12 & 14,87 & 14,93 \\
\hline
\end{tabular}

${ }^{(1)}$ Médias seguidas de mesma letra, na coluna, não diferem entre si pelo

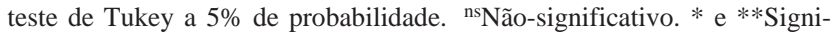
ficativo a $5 \%$ e a $1 \%$ de probabilidade, respectivamente, pelo teste F. do, com a cultivar IAC Carioca, num Latossolo Roxo em rotação com pousio, milho, aveia-preta, crotalária, guandu e mucuna-preta, Wutke et al. (2000) verificaram que na camada arável houve manutenção do teor
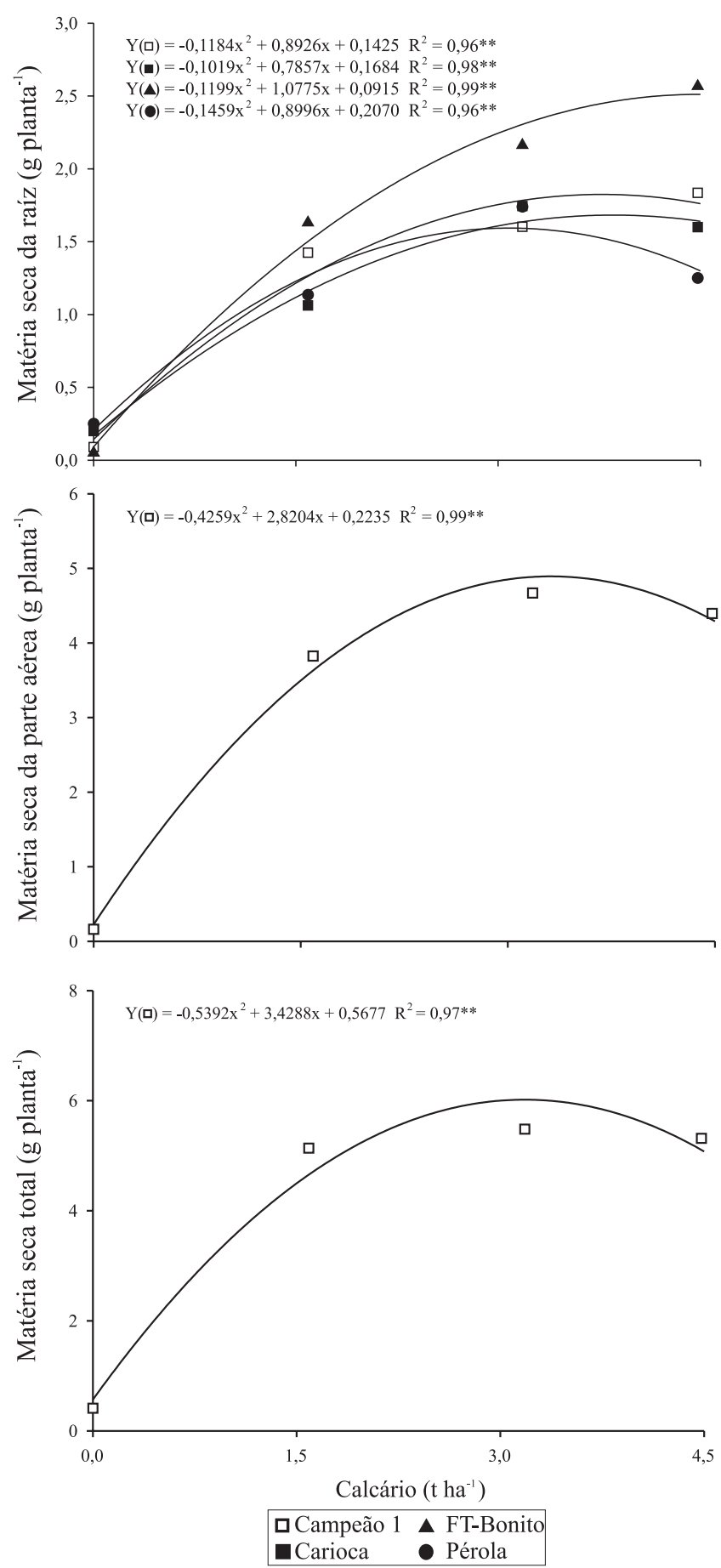

Figura 2. Matéria seca da raiz, da parte aérea e total (raízes + parte aérea) de cultivares de feijão, em razão das doses de calcário. 
de matéria orgânica do solo, bem como redução da acidez e aumento de saturação por bases, permitindo que a profundidade efetiva do sistema radicular atingisse 0,35 a $0,40 \mathrm{~m}$.

O aumento nos valores da massa de matéria seca do sistema radicular, da massa de matéria seca da parte aérea e da massa de matéria seca total (Figura 2) decorrente da calagem estão relacionados com o crescimento radicular (Figura 1), uma vez que, com o maior desenvolvimento radicular, provavelmente, ocorreu maior absorção de nutrientes.

Houve correlação positiva e significativa de $\mathrm{pH}$ e saturação por bases com comprimento radicular, superfície radicular, massa de matéria seca da raiz, massa de matéria seca da parte aérea e massa de matéria seca total, e correlação negativa e significativa de saturação por alumínio com essas variáveis (Tabela 4). Quanto ao diâmetro radicular, não observou-se correlação significativa com pH do solo, saturação por bases e saturação por alumínio nas cultivares Campeão 1 e Pérola. Nas cultivares Carioca e FT-Bonito, o diâmetro radicular apresentou correlação positiva e significativa com o pH do solo e correlação negativa e significativa com a saturação por alumínio.

Tabela 4. Coeficientes de correlação simples de pH do solo, saturação por bases (\%), e saturação por alumínio (m\%) com comprimento radicular (CRA), superfície radicular (SRA), diâmetro radicular (DRA), massa de matéria seca da parte aérea (MSPA), massa de matéria seca radicular (MSRA) e massa de matéria seca total (MST), das cultivares Campeão 1, Carioca, FT-Bonito e Pérola.

\begin{tabular}{|c|c|c|c|c|c|c|}
\hline Variável & 1 CRA & SRA & DRA & MSPA & MSRA & MST \\
\hline & \multicolumn{6}{|c|}{ Campeão 1} \\
\hline $\mathrm{pH}$ & $0,65^{* *}$ & $0,63 * *$ & $0,27^{\mathrm{ns}}$ & $0,63 * *$ & $0,61 *$ & $0,64 * *$ \\
\hline V\% & $0,68 * *$ & $0,65^{* *}$ & $0,36^{\mathrm{ns}}$ & $0,81 * *$ & $0,75 * *$ & $0,82 * *$ \\
\hline \multirow[t]{2}{*}{$\mathrm{m} \%$} & $-0,74 * *$ & $-0,72 * *$ & $-0,43^{\mathrm{ns}}$ & $-0,91 * *$ & $-0,80 * *$ & $-0,90 * *$ \\
\hline & \multicolumn{6}{|c|}{ Carioca } \\
\hline $\mathrm{pH}$ & $0,77 * *$ & $0,82 * *$ & $0,60 *$ & $0,79 * *$ & $0,89 * *$ & $0,84 * *$ \\
\hline $\mathrm{V} \%$ & $0,72 * *$ & $0,76 * *$ & $0,54 *$ & $0,78 * *$ & $0,83^{* *}$ & $0,82 * *$ \\
\hline \multirow[t]{2}{*}{$\mathrm{m} \%$} & $-0,76 * *$ & $-0,80 * *$ & $-0,59 *$ & $-0,85 * *$ & $-0,86 * *$ & $-0,88 * *$ \\
\hline & \multicolumn{6}{|c|}{ FT-Bonito } \\
\hline $\mathrm{pH}$ & $0,89 * *$ & $0,89 * *$ & $0,50 *$ & $0,82 * *$ & $0,93 * *$ & $0,89 * *$ \\
\hline $\mathrm{V} \%$ & $0,86^{* *}$ & $0,87 * *$ & $0,48^{\text {ns }}$ & $0,80 * *$ & $0,84 * *$ & $0,85 * *$ \\
\hline \multirow[t]{2}{*}{$\mathrm{m} \%$} & $-0,86 * *$ & $-0,87 * *$ & $-0,52 *$ & $-0,84 * *$ & $-0,86^{* *}$ & $-0,89 * *$ \\
\hline & \multicolumn{6}{|c|}{ Pérola } \\
\hline $\mathrm{pH}$ & $0,58 *$ & $0,54 *$ & $0,24^{\mathrm{ns}}$ & $0,84 * *$ & $0,55^{*}$ & $0,79 * *$ \\
\hline V\% & $0,70 * *$ & $0,67 * *$ & $0,32^{\mathrm{ns}}$ & $0,89 * *$ & $0,66 * *$ & $0,83 * *$ \\
\hline $\mathrm{m} \%$ & $-0,72 * *$ & $-0,70 * *$ & $-0,39^{\mathrm{ns}}$ & $-0,93 * *$ & $-0,68 * *$ & $-0,91 * *$ \\
\hline
\end{tabular}

\section{Conclusões}

1. A calagem promove aumento do sistema radicular e da parte aérea das cultivares de feijoeiro.

2. A cultivar Pérola apresenta sistema radicular mais tolerante à baixa saturação por bases.

3. As cultivares Campeão 1, Carioca e Pérola apresentam maior crescimento radicular quando a saturação por bases do solo é de $43 \%$.

4. As cultivares de feijão em condições de elevada acidez do solo reduzem o diâmetro radicular à custa do crescimento em comprimento.

\section{Agradecimento}

Ao CNPq pela concessão de bolsa ao autor Carlos Alexandre Costa Crusciol.

\section{Referências}

ADAMS, F.; MOORE, B.L. Chemical factors affecting root growth in subsoil horizons of Coastal Plain soils. Soil Science Society of America Journal, v.47, p.99-102, 1983.

EMBRAPA. Centro Nacional de Pesquisa de Solos (Rio de Janeiro, RJ). Sistema brasileiro de classificação de solos. Brasília: Embrapa-CNPS; Embrapa-SPI, 1999. 421p.

FAGERIA, N.K.; BALIGAR, V.C.; WRIGHT, R.J. Growth and nutrient concentration af alfafa and bean as influenced by soil acidity. Plant and Soil, v.119, p.331-334, 1989.

FAGERIA, N.K.; STONE, L.F. Manejo da acidez dos solos de cerrado e de várzea do Brasil. Santo Antonio de Goiás: Embrapa Arroz e Feijão, 1999. 42p. (Embrapa Arroz e Feijão. Documentos, 92).

INFORZATO, R.; MIYASAKA, S. Sistema radicular do feijoeiro em dois tipos de solo do Estado de São Paulo. Bragantia, v.22, p.477-481, 1963.

LYNCH, J.; BEEM, J.J. van. Growth and architecture of seedling root of common bean genotypes. Crop Science, v.33, p.1253-1257, 1993.

MALAVOLTA, E. Elementos de nutrição mineral de plantas. São Paulo: Agronômica Ceres, 1980. 256p.

RAIJ, B. van; ANDRADE, J.C.; CANTARELLA, H.; QUAGGIO, J.A. Análises químicas para avaliação da fertilidade de solos tropicais. Campinas: Instituto Agronômico, 2001. 285p.

RITCHEY, K.D.; SILVA, J.E.; COSTA, U.F. Calciun deficiency in clayey-B horizons of savanna Oxisols. Soil Science Society of America Journal, v.133, p.378-382, 1982.

ROSOLEM, C.A. Calagem e adubação mineral. In: ARAUJO, R.S.; RAVA, C.A.; STONE, L.F.; ZIMMERMANN, M.J.O. (Coord.). Cultura do feijoeiro comum no Brasil. Piracicaba: Potafos, 1996. p.353-385.

ROSOLEM, C.A. Interpretação dos teores de bases trocáveis do solo. In: BULL, L.T.; ROSOLEM, C.A. (Ed.). Interpretação de 
análise de solo e planta para fins de adubação. Botucatu: Fundação de Estudos e Pesquisas Agrícolas e Florestais, 1989. p.97-128.

ROSOLEM, C.A.; MARCELLO, C.S. Crescimento radicular e nutrição de soja em função da calagem e adubação fosfatada. Scientia Agricola, v.55, p.448-455, 1998.

ROSOLEM, C.A.; GIOMMO, G.S.; LAURENTI, R.L.B. Crescimento radicular e nutrição de cultivares de algodão em resposta a calagem. Pesquisa Agropecuária Brasileira, Brasília, v.35, p.827833, 2000.

ROSOLEM, C.A.; SCHIOCHET, M.A.; SOUSA, L.S.; WITACHER, J.P.T. Root growth and cotton nutrition as by liming and soil compaction. Communications in Soil Science and Plant Analysis, v.29, p.169-177, 1998.

ROSOLEM, C.A.; VALE, L.S.R.; GRASSI FILHO, H.; MORAES, M.H. Sistema radicular do milho em função da calagem e da compactação do solo. Revista Brasileira de Ciência do Solo, v.18, p.491-497, 1994.

SILVA, J.B.C.; NOVAIS, R.F; SEDIYAMA, C.S. Comportamento de genótipos de soja em solo com alta saturação de alumínio. Pesquisa Agropecuária Brasileira, v.19, p.287-289, 1984.

SOUSA JÚNIOR, J.O.; NASCIMENTO, C.W.A.; MARTINEZ, H.E.P. Resposta do feijoeiro em solução nutritiva a níveis de cálcio e magnésio na presença de alumínio. Pesquisa Agropecuária Brasileira, v.33, p.284-296, 1998.
TAYLOR, D.; ARKIN, G.F. Root zone modification fundamentals and alternatives. In: TAYLOR, D.; ARKIN, G.F. (Ed.). Modifying the root environment to reduce crop stress. St. Joseph: American Society of Agricultural Engineers, 1981. p.3-16.

THUNG, M.D.T.; OLIVEIRA, I.P. Problemas abióticos que afetam a produção de feijoeiro e seus métodos de controle. Santo Antonio de Goiás: Embrapa-CNPAF, 1998. 172p.

TIFFNEY, B.H.; NIKLAS, K.J. Clonal growth in land plants: a palaeobotanical perspective. In: JACKSON, J.B.C.; BUSS, L.W.; COOK, R.E. (Ed.). Population biology and evolution of clonal organisms. New Haven: Yale University Press, 1985. p.35-66.

VALE, L.S.R. Doses de calcário, desenvolvimento da planta: componentes de produção, produtividade de grãos e absorção de nutrientes de dois cultivares de feijão (Phaseolus vulgaris L.). 1994. 71p. Dissertação (Mestrado) - Universidade Estadual Paulista, Botucatu.

WUTKE, E.B.; ARRUDA, F.B.; FANCELLI, A.L.; PEREIRA, J.C.V.N.A.; SAKAI, E.; FUJIWARA, M.; AMBROSANO, G.M.B. Propriedades do solo e sistemas radicular do feijoeiro irrigado em rotação de culturas. Revista Brasileira de Ciência do Solo, v.24, p.621-633, 2000 .

WUTKE, E.B.; PIRES, R.C.M.; TANAKA, R.T.; SAKAI, E.; MASCARENHAS, H.A.A. Desenvolvimento vegetativo e radicular, rendimento de grãos e qualidade fisiológica de sementes de feijoeiro da seca após cultivo de adubos verdes, em plantio direto. Revista de Agricultura, v.78, p.77-91, 2003. 